\title{
Multistep Fractionation of Coal and Application for Graphene Synthesis
}

Kaustubh Rane, ${ }^{1}$ Jeramie J. Adams, ${ }^{2}$ James M. Thode, ${ }^{3 a}$ Brian M. Leonard, ${ }^{3}$ Jianqiang Huo, ${ }^{2 b}$ Lamia Goual ${ }^{1 *}$

${ }^{1}$ Department of Petroleum Engineering, University of Wyoming, 1000 E. University Avenue, Laramie, WY 82071

${ }^{2}$ Western Research Institute, 365 N 9 ${ }^{\text {th }}$ St., Laramie, WY 82072

${ }^{3}$ Department of Chemistry, University of Wyoming, 1000 E. University Avenue, Laramie, WY 82071

*Email: 1goual@uwyo.edu, Phone: (307) 766-3278

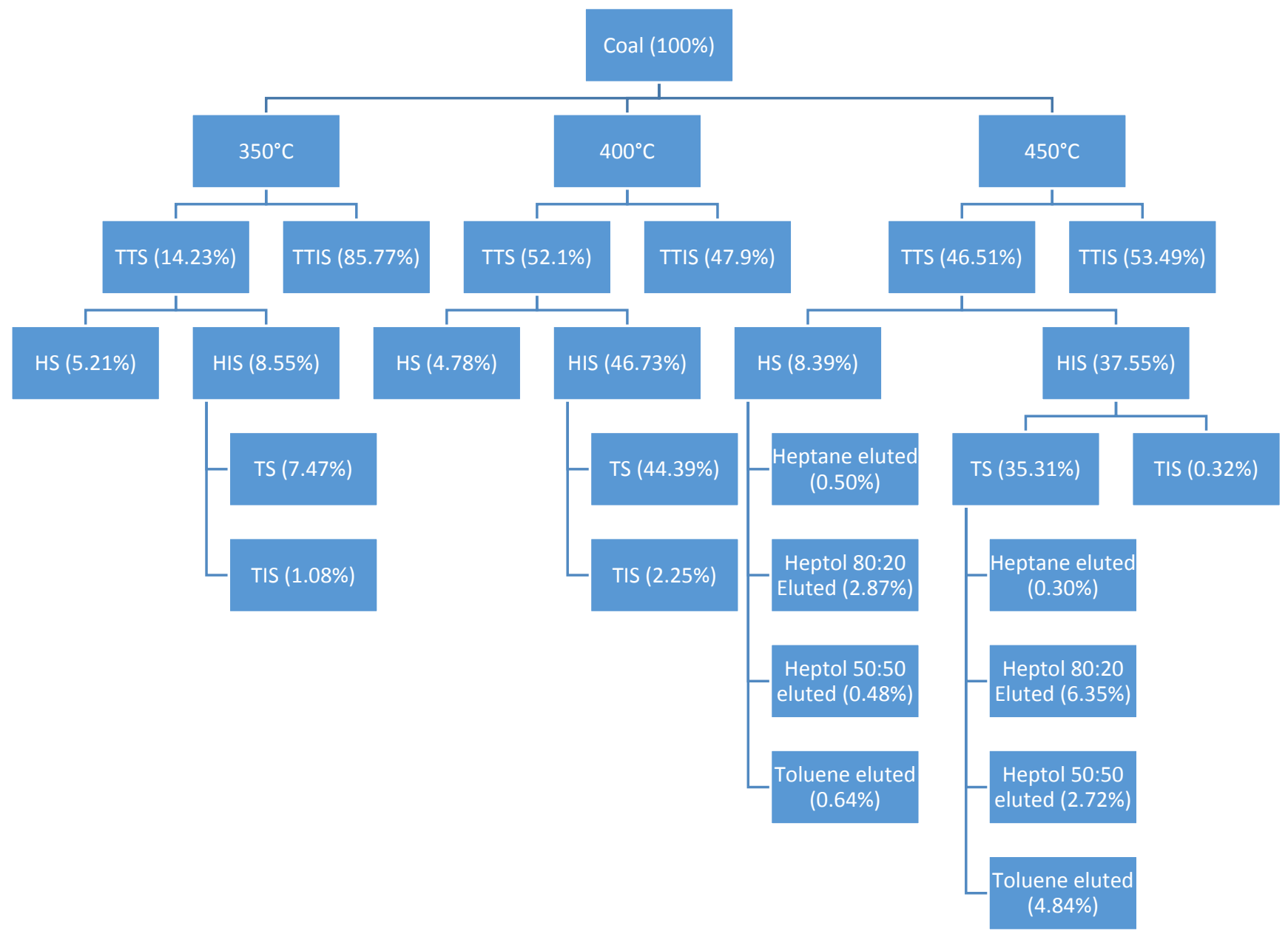

Figure S1: Conversion of the multistep coal fractionation

\footnotetext{
a Anton Paar USA, Inc. - Western Regional Office, 2824 Columbia Street, Torrance, CA 90503

${ }^{b}$ College of Chemistry and Chemical Engineering, Northwest Normal University, 967 Anning E Rd, Lanzhou, Gansu, China
} 